\title{
Design and implementation of a stability control system for TCP/AQM network
}

\author{
Salam Waley Shneen ${ }^{1}$, Mohammed Qasim Sulttan², Manal Kadhim Oudah ${ }^{3}$ \\ ${ }^{1}$ Energy and Renewable Energies Technology Center, University of Technology, Baghdad, Iraq \\ ${ }^{2,3}$ Electromechanical Department, University of Technology, Baghdad, Iraq
}

\begin{tabular}{l} 
Article Info \\
\hline Article history: \\
Received Sep 17, 2020 \\
Revised Jan 5, 2021 \\
Accepted Jan 29, 2021 \\
\hline
\end{tabular}

Keywords:

AQM

PI controller

PSO

TCP

\begin{abstract}
In this work, we used a new approach as active queue management (AQM) to avoid data congestion in TCP/IP networks. The new approach is PSO-PI controller which use the proportional-integral controller as a control unit and particle swarm optimization (PSO) algorithm as an optimization technique to improve the performance of the PI controller and therefore improving the performance of TCP/IP networks as a required goal. The optimization control (PSO-PI) is characterized by access to design and choosing the optimal parameters of (K_i andK_p) to reach optimal solutions in a short way (fewer iterations). The implementation of the PSO algorithm is achieving by using the mathematical system model and M-file and SIMULINK in Mathlab program. Simulation results show good congestion management performance with PSO-PI controller better than the PI controller as AQM in TCP networks, and the proposed method was very fast and required few iterations.
\end{abstract}

This is an open access article under the CC BY-SA license.

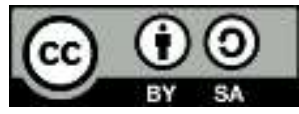

\section{Corresponding Author:}

Salam Waley Shneen

Energy and Renewable Energies Technology Center

The University of Technology

52 Al-Snaa street, Baghdad, Iraq

Email: 50054@uotechnology.edu.iq

\section{INTRODUCTION}

The increase in data circulating on the Internet and the increase in the number of Internet users has made the network more congested [1-3]. Among the problems that researchers work in the field of Internet use, such as buffer overflow for intermediate vectors, loss of packets and time delay in the delivery of packets [4-6]. To improve network performance, the use of transmission control protocol and active queue management (TCP / AQM). AQM was the main policy used for control [7-9]. To overcome these problems. The PSO algorithm is one of the distinctive methods used by researchers to solve nonlinearity and nondifferentiation problems and to improve performance to reach adaptation [10-12]. The first to suggest PSO algorithm is Kennedy and Eberhart [13]. It is a method for developing flock research, such as gathering birds and keeping fish [14, 15]. The optimization PSO is characterized by a combination of algorithms that improve performance better than others, which are good efficiency, relative simplicity, and stable convergence property [16-18]. Design PSO-PID as a control unit for performance estimation using the ITAE standard as one of the simplest and most time-saving applications for performance measurement [19-21]. The ITSE performance standard weighs errors over time, penalizes small errors at a later time and distinguishes large initial error in response. To design controllers under the goal of trying to reduce system error resulting from several predictable inputs [22-24]. System error is the difference between the desired response and the actual system response. Among the approved standards that determine performance are those that are mainly based on the error scale in the system [25-27]. In general, traditional controllers such as PID can be designed 
in such a way as to use one of the formats of a performance standard that includes (IAE), (ISE), (ITSE) or (ITAE) in control [28-30].

Qaradawi, S. et al. they used a PI controller with PSO as an AQM to avoid the congestion in computer networks, the simulation results appeared a good response time with a constant value of output [31]. Nayl, T. M., et al. they proposed a design AQM for TCP network consisted of (LQ)-servo controller with PSO method to reduce the delay time, fostering settling time and provide a stable queue length [32]. Li, Z. H. E., et al, they suggested a new AQM approach for a type of TCP network by using an integral backstepping technique (IB) and minimax procedure, the results showed a short convergent duration and deal with the disorders produced by UDP streams [33]. Kadhim, H. M., et al, they designed type-1 and type-2 fuzzy logic with PID controller to reduce the congestion in the TCP networks when they used optimization algorithms (PSO, SSO and ACO) to choose the parameters of two controllers, type-2 fuzzy logic with SSO has given good results [34].

This work proposes using a proportional integrity controller (PI) with algorithm (PSO) as an active queue manager for Internet routers. The goals of the work go toward fulfilling a stable queue length, improve latency to prevent TCP failure or slowing down. The structure of the paper is organized as follows, Section 2, include the Simulink model for TCP/AQM system. The simulation results wrote down in Section 3. The conclusion of this work wrote in Section 4.

\section{SIMULINK MODEL FOR TCP/AQM SYSTEM}

TCP/AQM network, in Figure 1 model System of TCP/AQM networks that includes routers, sources, and standardized control networks, Figure 2 schematic model System of a controller with AQM network and the system block diagram of TCP/AQM network in Figure 3.

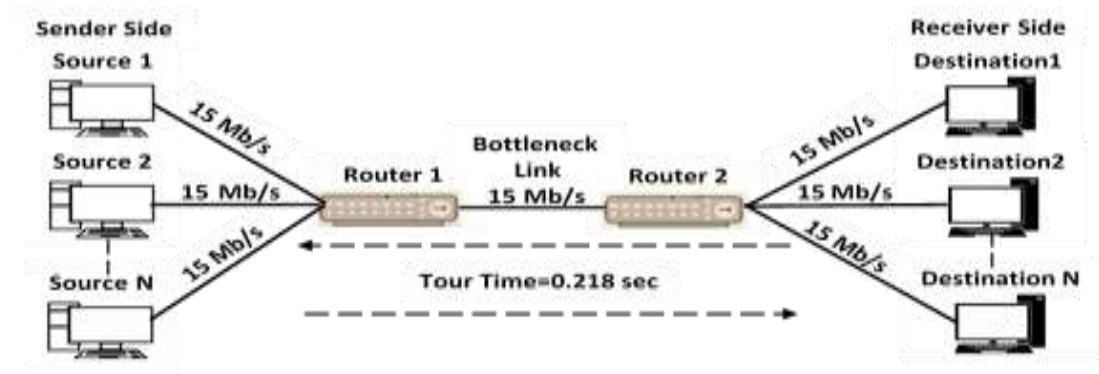

Figure 1. System of TCP / AQM networks

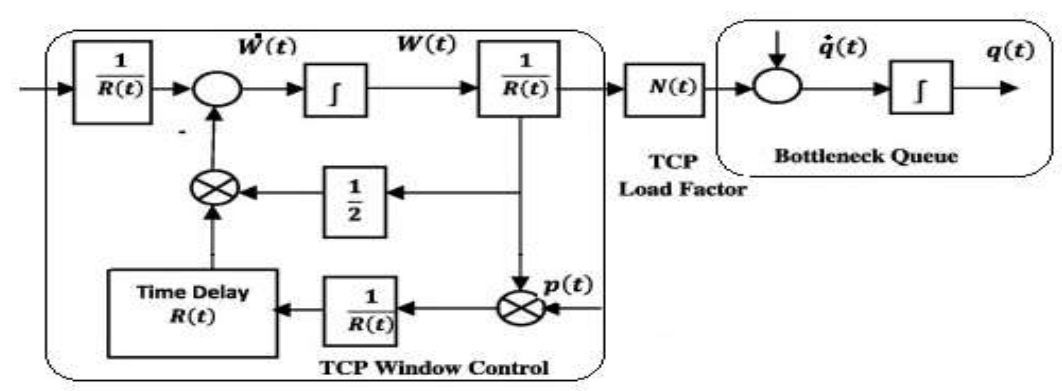

Figure 2. Schematic model of a controller with a TCP network

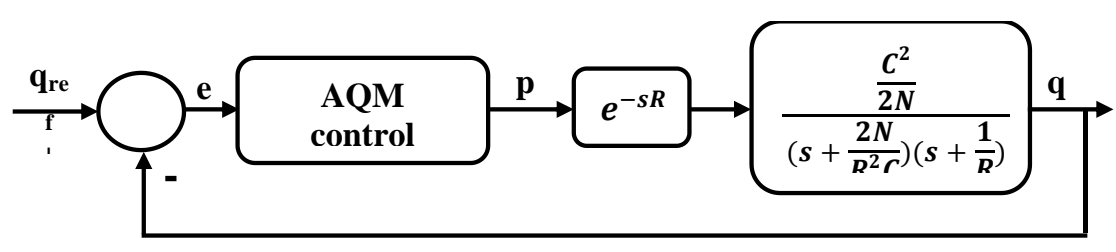

Figure 3. System block diagram of TCP/AQM network 
In this section, it had two parts first part is the Simulink model of the PI controller for TCP/AQM that show in Figure 4. The Simulink model of PI for TCP/AQM, it had input, PI controller, T.F of TCP/AQM and output. The second part is the Simulink model of PSO-PI for TCP/AQM shown in Figure 5. The Simulink model of PSO-PI for TCP/AQM, it had input, PI controller with ITAE, T.F of TCP/AQM and output. Table 1 showing the values of TCP/AQM network topology that we have adopted on our work. The mathematical model of the TCP network as shown in (1-6) [35-38]:

$$
\begin{aligned}
& " \dot{w}(t)=\frac{1}{\frac{q(t)}{C}+T_{p}}-\frac{w(t)}{2} \frac{w(t-R(t))}{\frac{q(t-R(t))}{C}+T_{p}} p(t-R(t)) " \\
& " \dot{q}(t)= \begin{cases}-C+\frac{N(t)}{\frac{q(t)}{C}+T_{p}} w(t) & \text { if } q(t)>0 \\
\max \left\{0,-C+\frac{N(t)}{\frac{q(t)}{C}+T_{p}} w(t)\right\} & \text { if } q(t)=0\end{cases} \\
& \frac{122.8 \mathrm{~s}^{3}+3299 \mathrm{~s}^{2}+2455 \mathrm{~s}+3.252 \mathrm{e}^{04}}{4} \\
& \mathrm{~s}^{4}+1.136 \mathrm{~s}^{3}+20 \\
& F(s)=\frac{q(s)}{p(s)}=\frac{\frac{\mathrm{C}^{2}}{2 \mathrm{~N}} \mathrm{e}^{-s R}}{\left(s+\frac{2 \mathrm{~N}}{\mathrm{R}^{2} \mathrm{C}}\right)\left(\mathrm{s}+\frac{1}{\mathrm{R}}\right)} \\
& \operatorname{sat}(\mathrm{p}(\mathrm{t}-\mathrm{R}(\mathrm{t})))=\left\{\begin{array}{cc}
1, & \mathrm{p}(\mathrm{t}-\mathrm{R}(\mathrm{t})) \geq 1 \\
\mathrm{p}(\mathrm{t}-\mathrm{R}(\mathrm{t})), & 0 \leq \mathrm{p}(\mathrm{t}-\mathrm{R}(\mathrm{t}))<1 \\
0, & \mathrm{p}(\mathrm{t}-\mathrm{R}(\mathrm{t}))<0
\end{array}\right.
\end{aligned}
$$

Where:

$\dot{w}$ and $\dot{q}$ is the time-derivative of $\mathrm{w}$ and q respectively.

$\mathrm{w}$ : Rate of TCP window size,

$\mathrm{R}$ : measured in seconds, $\mathrm{R}=\frac{\mathrm{q}}{\mathrm{C}}+\mathrm{T}_{\mathrm{p}}$

q: rate of queue length

C: Capacity of the link

$\mathrm{N}$ : Load factor

$\mathrm{T}_{\mathrm{p}}$ : Promulgation delay

p: Packet sign probability

$$
s(t)=K_{P} e(t)+K_{I} \int_{0}^{t} e(t) d t
$$

Where:

$\mathrm{e}(\mathrm{t})$ : The error signal between (the input reference and the process output) ec(t): The change of error signal

$K_{P}$ : Proportional constant gain

$K_{I}$ : Integral constant gain

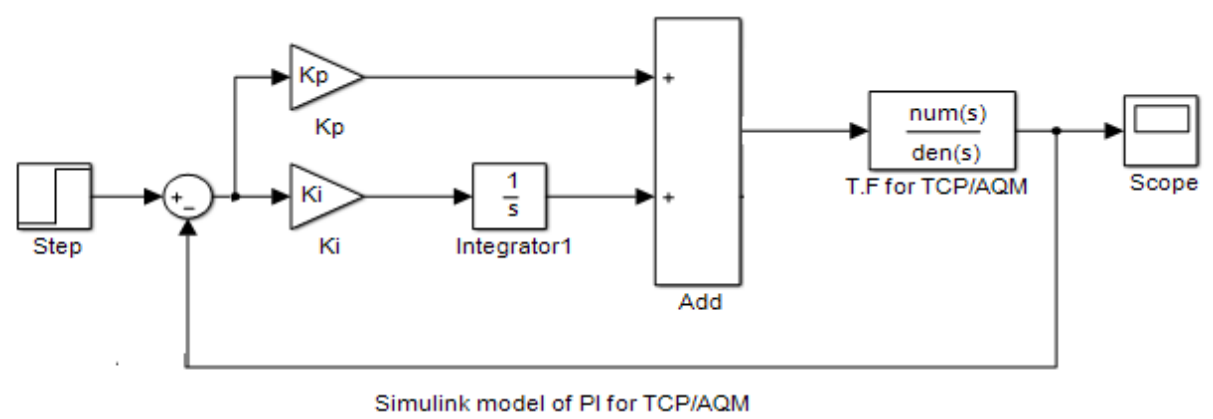

Figure 4. Simulink model of PI for TCP/AQM 


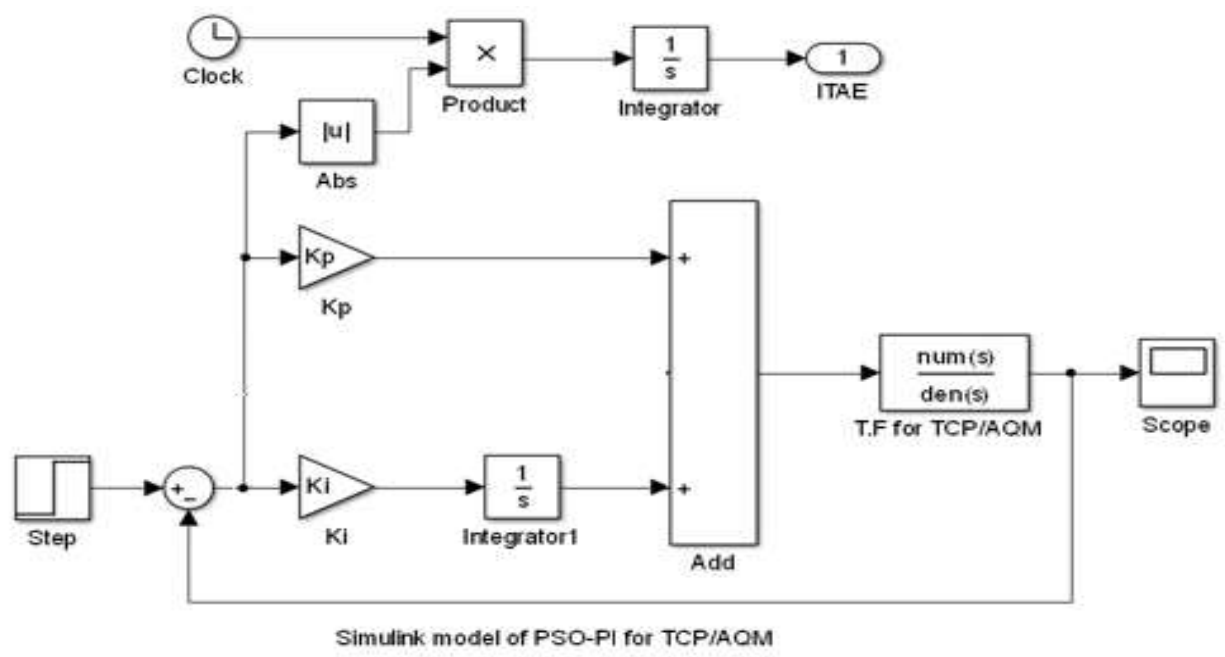

Figure 5. Simulink model of PSO-PI for TCP/AQM

Table 1. The TCP network parameter system

\begin{tabular}{|c|c|c|c|c|c|c|}
\hline $\mathrm{N}$ & $\mathrm{C}$ & $\begin{array}{l}\text { Packet } \\
\text { size }\end{array}$ & $\mathrm{Tp}$ & $\mathrm{R}$ & $\mathrm{q}_{\mathrm{des}}$ & $\mathrm{q}_{\max }$ \\
\hline $\begin{array}{c}60 \\
\text { (TCP session } \\
\text { number) }\end{array}$ & $\begin{array}{c}15 \mathrm{Mbps} \\
\text { (3750 packet/seconds } \\
\text { link capacity) }\end{array}$ & $\begin{array}{c}500 \text { byte } \\
-\end{array}$ & $\begin{array}{c}0.2 \text { seconds } \\
\text { (the propagation } \\
\text { delay) }\end{array}$ & $\begin{array}{l}0.253 \text { seconds } \\
\text { (the round-trip } \\
\text { time) }\end{array}$ & $\begin{array}{l}300 \text { packets } \\
\text { (the desired } \\
\text { queue size) }\end{array}$ & $\begin{array}{c}700 \text { packets } \\
\text { (maximumqueue } \\
\text { length in router } \\
\text { 1) }\end{array}$ \\
\hline
\end{tabular}

The traditional PI controllers are used in many applications for position and speed control, these controller methods need for re-tuning its parameters because it sometimes does not give better tuning and inclines to produce a large overshoot. To boost the abilities of PI parameter tuning, different intelligent techniques have been proposed to improve the PI tuning such as genetic algorithms (GA) [39-42], biogeography based optimization (BBO) [43-45], ant colony optimization (ACO) [46], bee colony optimization (BCO) [47], and PSO. The technique PSO was proposed in this work to tune the PI controller parameters to reach closely an optimal performance of PI controller to reduce the effect of congestion in TCP networks, for more details about PSO technique you can review Refs, [48-50]

\section{SIMULATION RESULTS}

In this section, the simulation results of this work are presented, it had two parts, the first part presents the Simulink results of PI controller for TCP/AQM that show through the Figures 6-9. The second part presents the Simulink results of PSO-PI controller for TCP/AQM that show in Figures 10, 11. The summary of all Simulink results was put in Table 2 with the important values that we got through Simulink circuits.

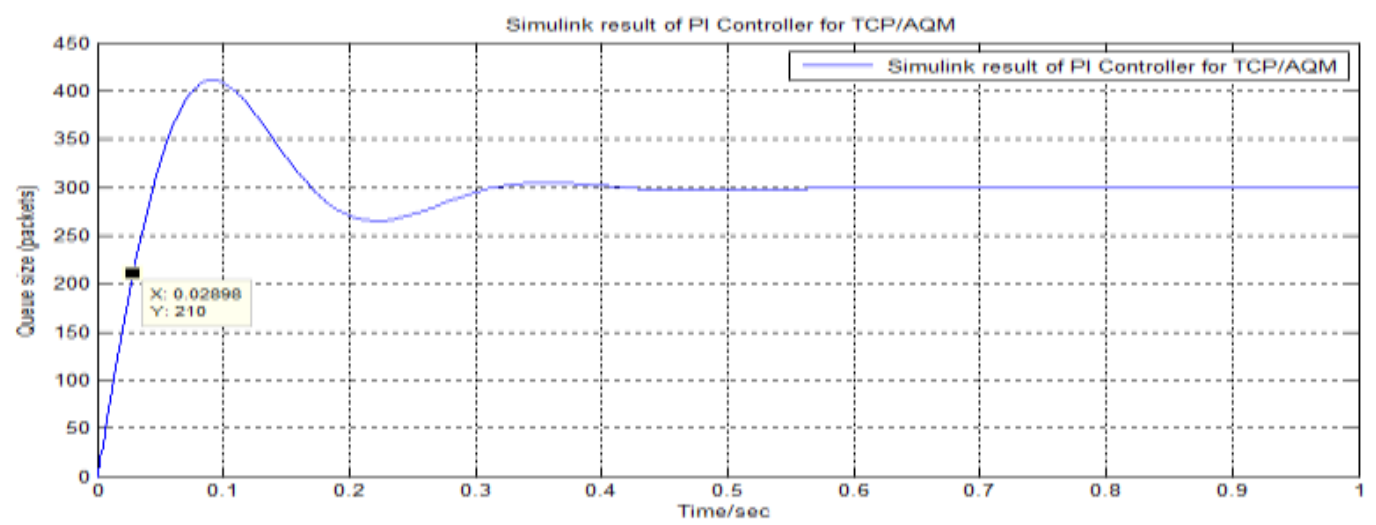

Figure 6. Simulation result of the PI controller for calculation of rising time $\left(\mathrm{t}_{\mathrm{r}}\right.$ ) 


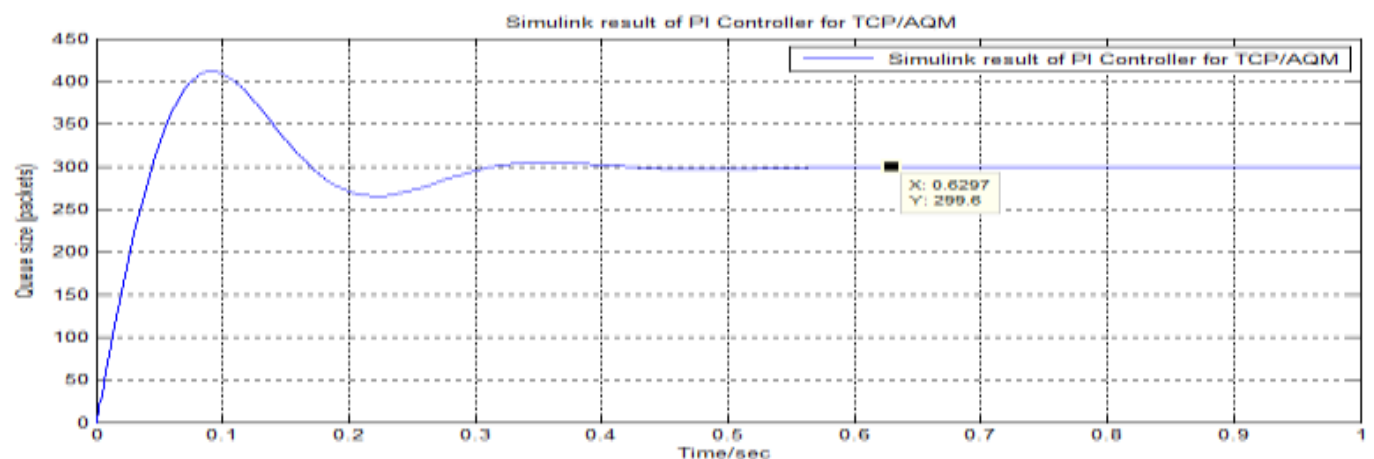

Figure 7. Simulation result of the PI controller at the calculation of steady state error $\left(\mathrm{t}_{\mathrm{ss}}\right.$.

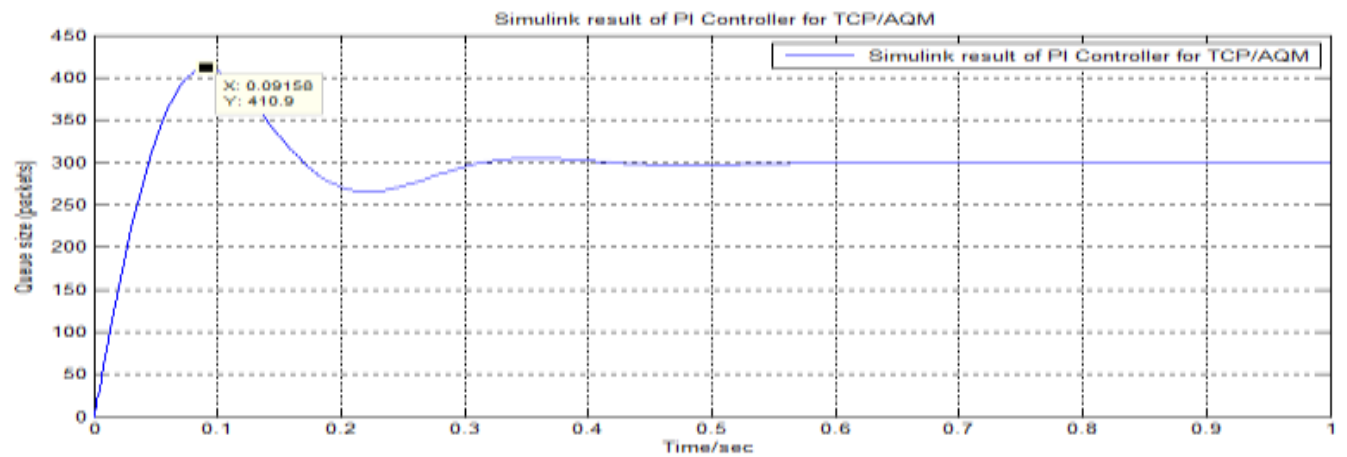

Figure 8. Simulation result PI controller for calculation of overshoot (\%)

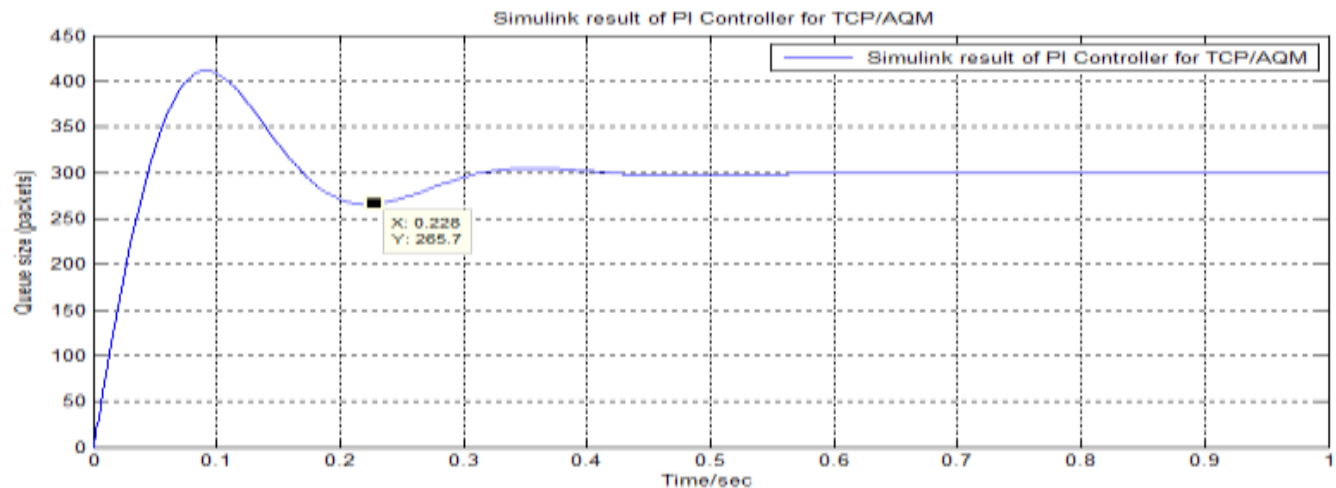

Figure 9. Simulation result PI controller for calculation of undershoot (\%)

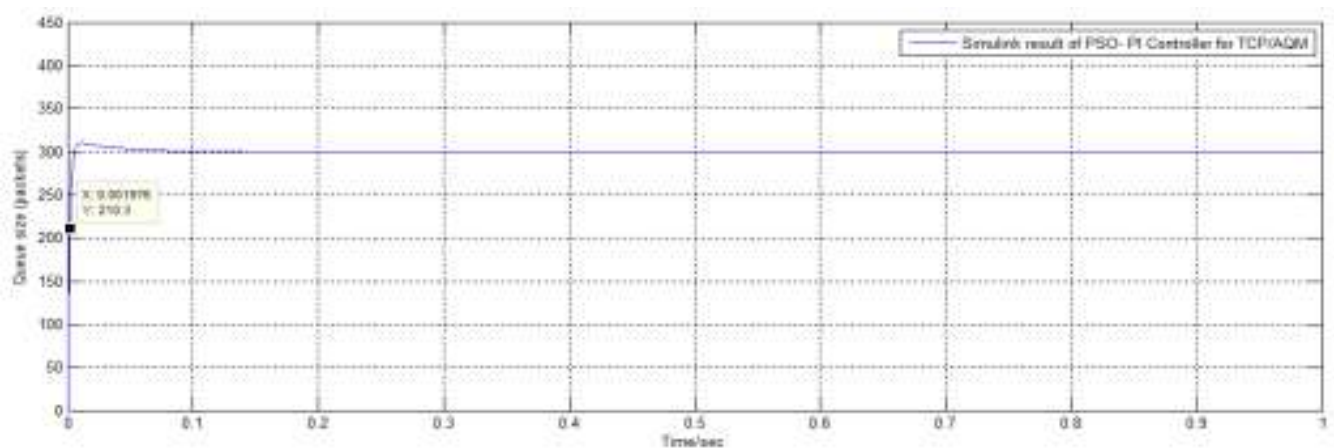

Figure 10. Simulation result of PSO-PI (ITAE) for calculation of rising time $\left(\mathrm{t}_{\mathrm{r}}\right)$ 


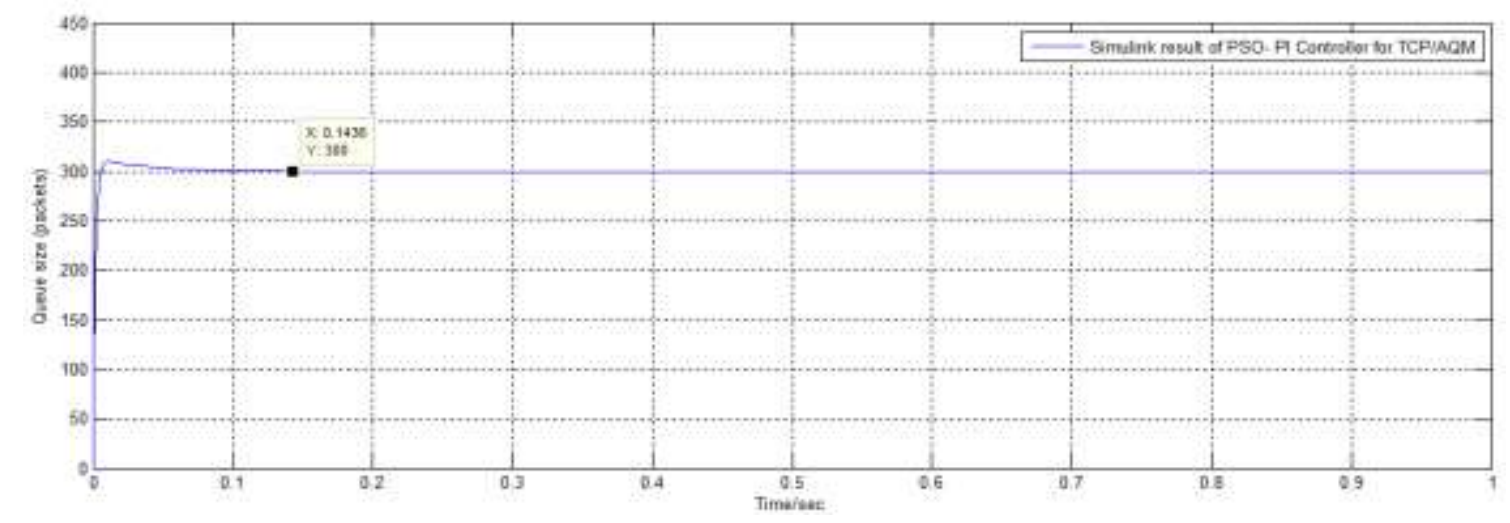

Figure 11. Simulation result of PSO-PI (ITAE) for calculation of steady state error $\left(\mathrm{t}_{\mathrm{ss}}\right.$.)

Table 2. The details of the simulation results with the figures that show these results

\begin{tabular}{|c|c|c|c|c|c|c|c|}
\hline $\begin{array}{l}\text { Type of } \\
\text { controller }\end{array}$ & $\mathrm{X}($ time $) / \mathrm{sec}$ & $\begin{array}{c}\text { Y (Queue size) } \\
\text { (packets) }\end{array}$ & $\mathrm{t}_{\mathrm{ss}}$ & $\mathrm{t}_{\mathrm{r}}$ & Overshoot & Undershoot & Figure \\
\hline $\mathrm{Pi}$ & 0.02898 & 210 & & 0.02898 & & & 6 \\
\hline $\mathrm{Pi}$ & 0.6297 & 299.6 & 0.6297 & & & & 7 \\
\hline $\mathrm{Pi}$ & 0.09158 & 410.9 & & & $(0.09158,410.9)$ & & 8 \\
\hline $\mathrm{Pi}$ & 0.228 & 265.7 & & & & $(0.228,265.7)$ & 9 \\
\hline Pso-pi & 0.00197 & 210.3 & & 0.00197 & & & 10 \\
\hline Pso-pi & 0.1436 & 300 & 0.1436 & & & & 11 \\
\hline
\end{tabular}

Step response of the PSO- PI controlling system is completely different from that of the conventional PI controlling system. As shown in Figures 6-11 and Table 1. When using PI controller, the Rising Time Value $=0.02898$, the Overshoot value $=410.9$ at Time Value $=0.09158$ and The Steady-State Error $=0.6297$. While when using PSO-PI controller the Rising Time value $=0.00197$, the Overshoot value $=$ 309.5 at Time Value $=0.009366$ and Steady-State Error $=0.1436$. The values $0.02701,0.4861$ and 101.4 are represented the difference of values for rising time, steady-state error, and Overshoot respectively when using PI and PSO-PI, these three values show the rang of optimization in the performance of TCP/AQM system when used the PSO technique with PI controller. Remarkably, the PSO-PI controller has improved the force servo system by inferring the optimized $k_{p}$ and $k_{i}$.

\section{CONCLUSION}

This work debate the design and implementation of the stability issue for TCP/AQM systems by using the PSO-PI controllers. According to simulation results, the designed PSO-PI controller can reduce the congestion problem with the best tracking execution for the desirable queue borders with high link exploitation and quicker response for the system. The simulation results showed that the step response of the PSO- PI controlling system is completely different from that of the conventional PI controlling system, the improvement in TCP/AQM systems work become clear especially if we note the difference between the values of rising time, steady-state error, and overshoot value in PI and PSO-PI controller. We can conclude that the use of PSO technique is very important to improve the performance of TCP/AQM systems due to the PSO-PI controller had improved the force servo system by deducing the optimized Kp and Ki.

\section{REFERENCES}

[1] Khudhair, A. A., Jabbar, S. Q., Sulttan, M. Q., \& Wang, D., "Wireless indoor localization systems and techniques: survey and comparative study," Indonesian Journal of Electrical Engineering and Computer Science (IJEECS), vol. 3, no. 2, pp. 392-409, 2016, doi: 10.11591/ijeecs.v3.i2.pp392-409.

[2] Sulttan, Mohammed Qasim, "Enhancement of K-Best Sphere Detection algorithm Performance in MIMO Systems," IOP Conference Series: Materials Science and Engineering, vol. 518, no. 5, IOP Publishing, 2019.

[3] Sulttan, Mohammed Qasim, "Impact of using Infinity-Norm with Initial Radius on Performance and Complexity of SD Algorithm in MIMO systems," International Journal Of Computers and Technology, vol. 15, no. 6, pp. 68576864, 2016, doi: 10.24297/ijct.v15i6.1614. 
[4] Bolot, Jean-Chrysotome, "End-to-end packet delay and loss behavior in the Internet," Conference proceedings on Communications architectures, protocols and applications, 1993, doi: 10.1145/166237.166265.

[5] Lun, Desmond S., et al., "On coding for reliable communication over packet networks," Physical Communication, vol. 1, no. 1, pp. 3-20, 2008, doi: 10.1016/j.phycom.2008.01.006.

[6] Mahajan, M., \& Kaur, S., "Congestion Control Protocols in Wireless Sensor Networks: a Comprehensive Survey," In 2020 International Conference on Intelligent Engineering and Management (ICIEM), pp. 160-164, IEEE, 2020, doi: 10.1109/ICIEM48762.2020.9160268.

[7] Wang, Kun, et al., "Adaptive fuzzy funnel congestion control for TCP/AQM network," ISA transactions, vol. 95, pp. 11-17, 2019, doi: 10.1016/j.isatra.2019.05.015.

[8] Wang, Kun, et al., "Study on TCP/AQM network congestion with adaptive neural network and barrier Lyapunov function," Neurocomputing, vol. 363, pp. 27-34, 2019, doi: 10.1016/j.neucom.2019.08.024.

[9] Ma, Lujuan, et al., "Congestion Tracking Control for Wireless TCP/AQM Network Based on Adaptive Integral Backstepping," International Journal of Control, Automation and Systems, vol. 18, no. 9, pp. 2289-2296, 2020, doi: 10.1007/s12555-019-0724-y.

[10] Deng, Wu, et al., "A novel intelligent diagnosis method using optimal LS-SVM with improved PSO algorithm," Soft Computing, vol. 23, no. 7, pp. 2445-2462, 2019, doi: 10.1007/S00500-017-2940-9.

[11] Shneen, Salam Waley, Chengxiong Mao, and Dan Wang, "Advanced optimal PSO, Fuzzy and PI controller with PMSM and WTGS at 5Hz side of generation and 50Hz Side of Grid," International Journal of Power Electronics and Drive Systems (IJPEDS), vol. 7, no. 1, p. 173, 2016, doi: 10.11591/ijpeds.v7.i1.pp173-192.

[12] Batool, Mouazma, Ahmad Jalal, and Kibum Kim, "Sensors Technologies for Human Activity Analysis Based on SVM Optimized by PSO Algorithm," 2019 International Conference on Applied and Engineering Mathematics (ICAEM). IEEE, 2019, doi: 10.1109/ICAEM.2019.8853770.

[13] Eberhart, R., \& Kennedy, J., "Particle swarm optimization," In Proceedings of the IEEE international conference on neural networks, vol. 4, pp. 1942-1948, 1995, doi: 10.1109/ICNN.1995.488968.

[14] Shi, Y., "Particle swarm optimization," IEEE connections, vol. 2, no. 1, pp. 8-13, 2004, doi: 10.1109/CEC.2001.934374.

[15] Shneen, Salam Waley, "Advanced Optimal for Three Phase Rectifier in Power-Electronic Systems," Indonesian Journal of Electrical Engineering and Computer Science (IJEECS), vol. 11, no. 3, pp. 821-830, 2018, doi: 10.11591/ijeecs.v11.i3.pp821-830.

[16] Bansal, J. C., "Particle swarm optimization," In Evolutionary and swarm intelligence algorithms, pp. 11-23, Springer, Cham. 2019.

[17] Cheng, S., Shi, Y., \& Qin, Q., "A study of normalized population diversity in particle swarm optimization,” In Handbook of Research on Advancements of Swarm Intelligence Algorithms for Solving Real-World Problems, pp. 345-381, IGI Global, 2020, doi: 10.4018/978-1-7998-3222-5.ch015.

[18] Valdez, F., Vazquez, J. C., Melin, P., \& Castillo, O., "Comparative study of the use of fuzzy logic in improving particle swarm optimization variants for mathematical functions using co-evolution," Applied Soft Computing, vol. 52, pp. 1070-1083, 2017, doi: 10.1016/j.asoc.2016.09.024.

[19] Bingul, Z., \& Karahan, O., "A novel performance criterion approach to optimum design of PID controller using cuckoo search algorithm for AVR system," Journal of the Franklin Institute, vol. 355, no. 13, pp. 5534-5559. 2018, doi: 10.1016/j.jfranklin.2018.05.056.

[20] Panwar, A., Sharma, G., Nasiruddin, I., \& Bansal, R. C., "Frequency stabilization of hydro-hydropower system using hybrid bacteria foraging PSO with UPFC and HAE," Electric Power Systems Research, vol. 161, pp. 74-85, 2018, doi: 10.1016/j.epsr.2018.03.027.

[21] Chen, J., Omidvar, M. N., Azad, M., \& Yao, X., "Knowledge-based particle swarm optimization for PID controller tuning," In 2017 IEEE Congress on Evolutionary Computation (CEC), pp. 1819-1826, IEEE. 2017, doi: 10.1109/CEC.2017.7969522.

[22] Parasuraman, R., \& Mouloua, M. (Eds.)., "Automation and human performance: Theory and applications," Routledge, 2018.

[23] Korda, M., \& Mezić, I., "Linear predictors for nonlinear dynamical systems: Koopman operator meets model predictive control," Automatica, vol. 93, pp. 149-160, 2018, doi: 10.1016/j.automatica.2018.03.046.

[24] Shneen, Salam Waley, Mohammed Qasim Sulttan, and Manal Hadi Jaber, "Variable speed control for 2Ph-HSM in RGS: a comparative simulation study," International Journal of Electrical and Computer Engineering (IJECE), vol. 10, no. 3, p. 2285, 2020, DOI: 10.11591/ijece.v10i3.pp2285-2295.

[25] Maghsoudi, M. J., Mohamed, Z., Husain, A. R., \& Tokhi, M. O., "An optimal performance control scheme for a 3D crane," Mechanical Systems and Signal Processing, vol. 66, pp. 756-768, 2016, doi: 10.1016/j.ymssp.2015.05.020.

[26] Nise, N. S., "Control systems engineering," John Wiley \& Sons, 2020.

[27] Dong, S., \& Chen, Y. C., "A method to directly compute synchronverter parameters for desired dynamic response," IEEE Transactions on Energy Conversion, vol. 33, no. 2, pp. 814-825, 2017, doi: 10.1109/TEC.2017.2771401.

[28] Ribeiro, J. M., Santos, M. F., Carmo, M. J., \& Silva, M. F., "Comparison of PID controller tuning methods: analytical/classical techniques versus optimization algorithms," In 2017 18th international Carpathian control conference (ICCC), pp. 533-538, IEEE. 2017, doi: 10.1109/CarpathianCC.2017.7970458.

[29] Arya, Y., "A novel CFFOPI-FOPID controller for AGC performance enhancement of single and multi-area electric power systems," ISA transactions, vol. 100, pp. 126-135, 2020, doi: 10.1016/j.isatra.2019.11.025.

[30] Arya, Y., "Automatic generation control of two-area electrical power systems via optimal fuzzy classical controller, Journal of the Franklin Institute, vol. 355, no. 5, pp. 2662-2688, 2018, doi: 10.1016/j.jfranklin.2018.02.004. 
[31] Qaraawy, S., Ali, H., \& Mahmood, A., "Particle swarm optimization-based robust controller for congestion avoidance in computer networks," In 2012 International Conference on Future Communication Networks, pp. 1822, IEEE. 2012, doi: 10.1109/ICFCN.2012.6206865.

[32] Nayl, T. M., \& Sabry, S. S., "Particle Swarm Optimization Based LQ-Servo Controller for Congestion Avoidance," Iraqi Journal of Computers, Communication and Control \& Systems Engineering, vol. 19, no. 1, pp. 63-70, 2019.

[33] Li, Z. H., Liu, Y., \& Jing, Y. W., "Active queue management algorithm for TCP networks with integral backstepping and minimax," International Journal of Control, Automation and Systems, vol. 17, no. 4, pp. 10591066, 2019, doi: 10.1007/s12555-018-0447-5.

[34] Kadhim, H. M., \& Oglah, A. A., "Interval type-2 and type-1 Fuzzy Logic Controllers for congestion avoidance in internet routers," In IOP Conference Series: Materials Science and Engineering, vol. 881, no. 1, p. 012135. IOP Publishing. 2020, doi: 10.1088/1757-899X/881/1/012135.

[35] Ariba, Y., Gouaisbaut, F., Rahme, S., \& Labit, Y., "Robust control tools for traffic monitoring in TCP/AQM networks," arXiv preprint arXiv:0902.0926. 2009.

[36] Sabry, S. S., \& Kaittan, N. M., "Grey wolf optimizer based fuzzy-PI active queue management design for network congestion avoidance," Indonesian Journal of Electrical Engineering and Computer Science (IJEECS), vol. 18, no. 1, pp. 199-208, 2020, doi: 10.11591/ijeecs.v18.i1.pp199-208.

[37] Shneen, Salam Waley, "Advanced optimal for power-electronic systems for the grid integration of energy sources," Indonesian Journal of Electrical Engineering and Computer Science (IJEECS), vol. 1, no. 3, pp. 543-555, 2016, doi: 10.11591/ijeecs.v1.i3.pp543-555.

[38] Hollot, C. V., \& Chait, Y., "Nonlinear stability analysis for a class of TCP/AQM networks," In Proceedings of the 40th IEEE Conference on Decision and Control (Cat. No. 01CH37228), vol. 3, pp. 2309-2314, IEEE. 2001, doi: 10.1109/CDC.2001.980604.

[39] Hollot, C. V., Misra, V., Towsley, D., \& Gong, W., "Analysis and design of controllers for AQM routers supporting TCP flows," IEEE Transactions on automatic control, vol. 47, no. 6, pp. 945-959, 2002, doi: 10.1109/TAC.2002.1008360.

[40] Liu, L., Moayedi, H., Rashid, A. S. A., Rahman, S. S. A., \& Nguyen, H., "Optimizing an ANN model with genetic algorithm (GA) predicting load-settlement behaviours of eco-friendly raft-pile foundation (ERP) system," Engineering with Computers, vol. 36, no. 1, pp. 421-433, 2020, doi: 10.1007/s00366-019-00767-4.

[41] Dorigo, M., \& Stützle, T., "Ant colony optimization: overview and recent advances," In Handbook of metaheuristics, pp. 311-35, Springer, Cham. 2019.

[42] Jovanović, A., Nikolić, M., \& Teodorović, D., "Area-wide urban traffic control: A Bee Colony Optimization approach," Transportation Research Part C: Emerging Technologies, vol. 77, pp. 329-350, 2017, doi: 10.1016/j.trc.2017.02.006.

[43] Ma, H., Simon, D., Siarry, P., Yang, Z., \& Fei, M., "Biogeography-based optimization: a 10-year review," IEEE Transactions on Emerging Topics in Computational Intelligence, vol. 1, no. 5, pp. 391-407, 2017, doi: 10.1109/TETCI.2017.2739124.

[44] Salam Waley Shneen, Hashmia Sh.Dakheel, Zainab B.Abdulla, "Design and implementation of variable and constant load for induction motor," International Journal of Power Electronics and Drive System (IJPEDS), vol. 11, no. 2, pp. 762-773, 2020, doi: 10.11591/ijpeds.v11.i2.pp762-773.

[45] Marini, F., \& Walczak, B., "Particle swarm optimization (PSO)," A tutorial. Chemometrics and Intelligent Laboratory Systems, vol. 149, pp. 153-165, 2015, doi: 10.1016/j.chemolab.2015.08.020.

[46] Waley, Salam, Chengxiong Mao, and Nasseer K. Bachache, "Biogeography based optimization for tuning FLC controller of PMSM," International Conference in Swarm Intelligence. Springer, Cham, 2015, doi: 10.1007/978-3319-20466-6_42.

[47] Galvan, D., Cremasco, H., Mantovani, A. C. G., Bona, E., Killner, M., \& Borsato, D., "Kinetic study of the transesterification reaction by artificial neural networks and parametric particle swarm optimization," Fuel, vol. 267, p. 117221, 2020, doi: 10.1016/j.fuel.2020.117221.

[48] Attiya, Adnan Jabbar, Yang Wenyu, and Salam Waley Shneen, "Compared with PI, Fuzzy_PI \& PSO_PI Controllers of Robotic Grinding Force Servo System," TELKOMNIKA (Indonesian Journal of Electrical Engineering), vol. 16, no. 1, pp. 65-74, 2015, doi: 10.11591/telkomnika.v16i1.8499.

[49] Shneen, Salam Waley, "Advanced Optimal for PV system coupled with PMSM," Indonesian Journal of Electrical Engineering and Computer Science (IJEECS), vol. 1, no. 3, pp. 556-565, 2016, doi: 10.11591/ijpeds.v7.i1.pp173192.

[50] Oudah, Manal Kadhim, Mohammed Qasim Sulttan, and Salam Waley Shneen, "Fuzzy type 1 PID controllers design for TCP/AQM wireless networks," Indonesian Journal of Electrical Engineering and Computer Science (IJEECS), vol. 12, no. 1, pp. 118-127, 2021, doi: 10.11591/ijeecs.v21.i1.pp118-127. 